\title{
Reflexiones acerca del sindicalismo nicaragüense (1970-2015)
}

Jorge Guerra Vanegas

Recepción: 05-02-2016/ Aceptación: 22-04-2016

\section{Resumen}

El sindicalismo nicaragüense durante el período de 1970 hasta la actualidad, cruzando por diversos regímenes, ha jugado un papel relevante en la historia nacional y este trabajo pretende hacer un recuento de este movimiento en los últimos tiempos. Durante el periodo en estudio, el movimiento sindical aprovechando las oportunidades estructurales ha echando mano de repertorios tales como huelgas, acciones amadas, alianzas, negociaciones con el fin de hacer sentir su presencia en el escenario político nacional. Una de las características de este movimiento social es que su acción colectiva se consolida en momentos de crisis sociales, políticas y económicas. La conquista de los derechos sociales y politicos: libertad sindical, seguro social, jornada salarial, entre otros es uno de las grandes aportes del sindicalismo a la historia contemporánea nicaragüense. Con la derrota electoral del FSLN en 1990, la estructuras de oportunidades cambian, y con ello los repertorios de confrontación. En este nuevo escenario se producen alianzas, negociaciones y huelgas como también un debilitamiento del movimiento sindical ante las políticas de ajuste estructural de la época. En estos últimos años se dan expresiones novedosas de sindicalismo: Confederación de trabajadores por cuenta propia y el Movimiento de Mujeres de las maquilas, importantes en la historia reciente del sindicalismo, presentando con ello nuevas formas de acción colectiva en un nuevo contexto de la realidad nacional.

Palabras claves: Movimiento sindical, Revolución Popular Sandinista, Movimiento de mujeres de la maquila, Confederación de trabajadores por cuenta propia.

\begin{abstract}
:
The Nicaraguan labor movement during the period 1970, to the present despite political situation has played an important role in the history of national. This paper aims to recount this movement in recent times. During the research period the labor movement taking advantage of structural opportunities has led strikes, armed actions, alliances, negotiations in order to make their presence felt on the national political scene. One of the characteristics of this social movement is that their collective action consolidates in periods of social, political and economic crisis. To achieve social and political rights: freedom of association, social security, working hours, among others, is one of the great contributions of of syndicalism to the Nicaraguan contemporary history. With the electoral defeat of the FSLN in 1990, the opportunity structures changed, and thus the repertoires of confrontation. In this new scenario alliances, negotiations and strikes occurred as well as a weakening of the trade union movement due to the structural adjustment policies of that period. Thus, innovative expressions of unionism are given: Confederation of self-employed, and the Women's Movement of the maquilas, important in the recent history of syndicalism, thereby presenting new forms of collective action in a new context of national reality.
\end{abstract}

Keywords: Labor movement, Popular Sandinista Revolution, Women's Movement of the maquilas, Confederation of self-employed. 


\section{Introducción}

Esta idea nace en el contexto de una investigación más general titulada: Movimientos sociales y Acción Colectiva en Nicaragua, llevada a cabo por el Centros de Análisis Sociocultural (CASC) de la Universidad Centroamericana en el 2015. En concordancia con ello decidí analizar detalladamente la evolución de la acción colectiva del movimiento sindical, tomando como punto de partida la década de los setenta hasta el primer decenio del siglo XXI. Así, esta acción colectiva se investiga como la manifestación organizada y sostenida de un movimientosocial. Dentrodeesta perspectiva, el movimiento sindical ha jugado un papel protagónico en la reivindicación de espacios económicos, políticos, y culturales, influidos por una serie de factores sociopolíticos de su historia reciente.

En este contexto, el sindicalismo nicaragüense presenta experiencias $y$ prácticas reivindicativas de mucho interés sociopolítico para la sociología. En este ámbito lo que interesa estudiar acerca del movimiento sindical son factores como la identidad, la acción colectiva, los repertorios y las estructura de oportunidades en el marco de la contienda política acontecida en los contextos de los setenta, ochenta, noventa, y dos mil. En correspondencia a este interés, se pretende identificar la manera en que la interacción de estos factores sociopolíticos contribuye a la construcción de un proyecto de izquierda. Así con base a dicha idea, se establecen las siguientes interrogantes ¿Cómo se ha caracterizado la acción colectiva del sindicalismo en las décadas mencionadas? ¿Qué plataformas sociopolíticas han influido en el sindicalismo nicaragüense? y ¿Cuál ha sido la vinculación histórica del FSLN con los sindicatos?

\section{Metodología usada y sustento teórico}

Se trata de una investigación en el marco de la Sociología Política con enfoque documental (Sautu, Boniolo, Dalle \& Elbert, 2005) y socio histórico (McAdam, Tarrow \& Tilly, 2005), Se realizó una revisión de la literatura científica sobre el tema. Así mismo se operacionalizó las categorías presentes en el marco teórico y se realizó entrevistas semiestructuradas a expertos y actores del sindicalismo de izquierda. La información se procesó a través de tablas de salidas cuyos resultados se analizaron en base a los objetivos, evidencia empírica, y el marco teórico.

En este marco es importante definir primero al sindicalismo como un movimiento social Pero, ¿Qué entenderemos por movimiento social? Se entenderá al "conjunto histórico, concreto, interconectado de interacciones y prácticas políticas a la combinación única de campañas, repertorios y demostraciones" (Tilly, 2007, p.29). En este contexto, la acción colectiva en los movimientos sociales como el sindicalismo se define como la actuación conjunta y deliberada de un grupo de personas con el objetivo deconseguir intereses comunes (Aya, 1995). Cuando esta acción colectiva tiene la finalidad de reivindicar determinados intereses a través de la apropiación de estructuras de oportunidades frente a un actor gubernamental, se establece la dinámica de la contienda política. Para Tilly (2007), la contienda política se trata de acciones reivindicativas discontinuas, públicas y colectivas en las que influyen los repertorios de confrontación, dividiéndose la contienda en dos tipos: contenida y transgresiva. La contienda contenida consiste en la acción colectiva de actores previamente establecidos que desarrollan su acción colectiva en el marco de las reglas formales del sistema político. La contienda transgresiva trata de la emergencia de nuevos actores en el escenario público, cuyas acciones colectivas consisten en actividades innovadoras (Tilly, 2007). 
Los repertorios, por su parte, son la totalidad de medios: lucha armada, huelgas de hambre, toma de edificios, bloqueo de calles, entre otros, pertenecientes a una cultura pública e histórica determinada, los cuales, a su vez, dependen de la apropiación de las redes sociales (flujo de información, recursos, actores y organizaciones), símbolos culturales e ideología que nutren o inspiran la movilización (Tarrow, 1997). Así, hay una estrecha relación entre la eficacia de los repertorios y el aprovechamiento de las estructuras de oportunidades. Esta última consiste en la apertura de las plataformas del acceso al poder, los cambios de lineamientos gubernamentales, la disponibilidad de aliados influyentes y la división dentro de las elites (Tarrow,1997).

La categoría izquierda por otra parte nos ayuda a entender la identidad particular del sindicalismo nicaragüense en el universo de movimientos sociales y comprender a su vez los móviles ideológicos que han influido en la acción colectiva. En correspondencia a ello Norberto Bobbio (2000) define como izquierda a todos aquellos movimientos sociales y políticos cuya reivindicación central es la igualdad social, política, económica y cultural de los seres humanos, por tanto, "El elemento que caracteriza a las doctrinas y los movimientos que se han llamado izquierda y como tales se han reconocido; es el igualitarismo" (Bobbio, 2000, p.30). Un movimiento de izquierda en esta perspectiva es aquel que reivindica una visión horizontal contra las desigualdades sociales, políticas, económicas y culturales que se generan en la sociedad.

En esta lógica, los movimientos de izquierda como el sindicalismo plantean la igualdad como condición necesaria para la libertad, siendo importante en este proceso las reivindicaciones socioeconómicas como la jornada laboral, el aumento de los salarios, la flexibilización laboral, el seguro social, entre otros. A este respecto Bobbio (2000) nos menciona:
Lo igualitario parte de la convicción de que la mayor parte de las desigualdades que lo indignan y querrían hacer desaparecer, son sociales y como tales eliminables, los no igualitarios en cambio parte de la convicción opuesta que son naturales y como tales no eliminables (p.25).

Recordemos que los proyectos políticos de izquierda se han redefinido y revitalizado en el mundo del siglo XXI. Sin embargo, las reivindicaciones en torno a la distribución, control y generación la riqueza económica continúa siendo parte fundamental de los ejes programáticos de esta corriente política. En este contexto, la derecha desde una polaridad contraria aprecia como negativa a la igualdad social considerando las desigualdades socioeconómicas como naturales, justas y eternas (Bobbio, 1995).

Para autores como Torrez y Gomáriz (2007), si bien la izquierda se define por la defensa de la igualdad esta no debe ser entendida como igualitarismo, pues en el contexto actual los movimientos políticos de izquierda reivindican tanto la libertad como la igualdad .En dicha lógica, estos valores se manifiestan en: 1) La lucha contra la desigualdad realmente existente, 2) La actuación contra la conculcación de la libertad que supone con frecuencia la libertad de acción de los más poderosos. Lo anterior supone la necesidad política por democratizar las relaciones sociales de los seres humanos que exigen como imperativos la emergencia de nuevos valores morales en la sociedad. En este sentido:

La izquierda ha usado mucho más la idea de solidaridad para hablar de las relaciones entre las personas, que la idea de fraternidad. Quizás sea un valor a recuperar en las relaciones entre las distintas culturas e identidades, en un mundo tan desbocado como el presente (Torrez y Gomariz, 2007, p.33). 


\section{Desarrollo del tema}

La historia de los movimientos sociales, en particular del sindicalismo nicaragüense, tiene como antecedente inmediato la acción colectiva encabezada por el FSLN contra la dictadura somocista .En este marco:

El movimiento social desde su propia gestación siempre fue político, y que fue precisamente ese movimiento el que generó como consecuencia de la lucha y de la maduración de las ideas terminó en un partido político de Nicaragua. Esa es la experiencia, que creo yo que hay que entenderla; que hay una simbiosis metida entre partido político de izquierda y movimiento sindical. (Barrantes, Comunicación personal 2 de abril, 2015). ${ }^{1}$

Fue en este ese período que surgieron organizaciones de trabajadores vinculadas a las tres tendencias del FSLN: los Comités Obreros Revolucionarios (COR) ligados a la Tendencia Proletaria (TP), el Movimiento Sindical Pueblo Trabajador (MSPT) articulados a la tendencia Guerra Popular Prolongada (GPP), y los Comités de Luchas de los Trabajadores (CLT) vinculados a la Tendencia Tercerista (TT) (Guevara 2008). Con relación a los trabajadores del campo, dos años más tarde (1976) proliferaron organizaciones sindicales como los Comités de Trabajadores del Campo (CTC), ubicados en zonas rurales de los departamentos de Carazo, León y Chinandega. En esta etapa, la represión de la dictadura obligó a los movimientos de trabajadores a combinar repertorios como la lucha social y laboral (en las calles), con la lucha guerrillera (campo-ciudad), De ahí que una parte de la movilización de los trabajadores pasó a la clandestinidad, estrechándose así su colaboración con el FSLN. Además, se dieron alianzas con la clase media, la intelectualidad, y un sector de la iglesia y la burguesía, entre otros, porque se llegó a la conclusión que solo una plataforma amplia de diversos sectores podría hacerle frente a la dictadura (Vilas, 1987 \& 1986). La conformación de esta gran alianza posibilitó el derrocamiento de la dictadura, dando nacimiento a un proyecto de transformaciones en el que cada movimiento social tenía su propio lugar en lo relativo a sus demandas y reivindicaciones (Gutiérrez, 1985; Guevara, 2008). Este proyecto de transformación se caracterizó por dinamizar al movimiento de trabajadores, ya que en su lucha contra el somocismo demostró la habilidad para contrarrestar los obstáculos del régimen, aprovechando las estructuras de oportunidades a partir de la alianza con otros actores y la diversificación y expansión del mismo movimiento, en un conjunto de repertorios de lucha, que transitaron de las formas más cívicas a las más violentas, como fue la lucha armada. De esta manera, la característica fundamental del movimiento sindical en este periodo es la combinación de la contienda contenida y la contienda transgresiva contra la Dictadura.

En el nuevo contexto, la Revolución Popular Sandinista (1979) generó aperturas de estructuras de oportunidades para la emergencia, crecimiento y participación del sindicalismo nicaragüense. Entre las reivindicaciones que el Estado Revolucionario apoyó, se destacan las concernientes a la tenencia de la tierra, estabilidad laboral, acceso al crédito y a la tecnología, entre otras. De ahí que en esta época el Estado llegó a poseer 351 empresas estatales que representaron entre el 30\% y $40 \%$ del Producto Interno Bruto (PIB) de la economía nacional. Así mismo, el crecimiento de las organizaciones de trabajadores fue tal que para 1978 solo existían 138 sindicatos con 27,020 trabajadores afiliados, mientras que

1 Es importante destacar que los fragmentos de las entrevistas que se utilizan en este trabajo son parte de un trabajo más amplio: Acción Colectiva y Movimientos Sociales en Nicaragua (2015) del Centro de Análisis sociocultural de la Universidad Centroamericana. 
para 1982 ya existían 1,200 nuevos sindicatos con aproximadamente 90,000 afiliados. Es así, que el crecimiento de la fuerza laboral sindicalizada pasó de $11 \%$ ó $12 \%$ en 1979 al $56 \%$ en 1986. Paralelamente, también crecieron organizaciones de trabajadores provenientes del sector rural, que para 1981 ya contaban con 30,000 afiliados (Vilas, 1987, p.247). Estos datos demuestran que durante la Revolución las organizaciones de trabajadores crecieron exponencialmente. Este crecimiento fue tal que de acuerdo al líder sindical Roger Barrantes las estructuras de oportunidades eran muy distintas al somocismo:

Antes del triunfo las organizaciones que teníamos eran débiles, clandestinas muy pequeñas. Cuando llegaba el triunfo todo el mundo comenzó a organizarse en sindicatos y se comenzaron a organizar ya de manera legal la Central Sandinista de Trabajadores, que era la que tenía toda la industria. Se llegó a organizar ya legalmente la Asociación de Trabajadores del Campo. Ya había FET - Salud, dos años antes pero era muy débil, muy fraccionaria en condiciones de clandestinidad, con el triunfo de la revolución la organización de trabajadores de la salud toma auge, los trabajadores de la educación con ese ejemplo de Ricardo Morales Avilés y de todos los otros compañeros se establece ya en una lógica diferente, en una lógica de libertad. (Comunicación personal 2 de abril, 2015).

Durante la revolución, las organizaciones de trabajadores ampliaron sus filas significativamente. La fuerza política del sindicalismo se regían bajo la lógica de una concepción centralizada, desde el punto de vista político e ideológica, por el FSLN que asumía el papel de vanguardia (Middlebrook, 1997). Un ejemplo emblemático de esta praxis fue el caso de la defensa militar, donde la participación del sindicalismo nicaragüense en 1984 fue de $34 \%$ de los miembros de la Asociación de Trabajadores del Campo (ATC), aproximadamente 20,000 miembros, participaban en las estructuras militares en defensa de la revolución.

Lo mismo sucedió con la Central Sandinista de Trabajadores (CST), llegando a tener al $47 \%$ de sus miembros en labores militares (Vilas, 1987). Las actividades de defensa militar por parte del movimiento, propició que gran parte del trabajo organizativo no estuviera abocado a las labores habituales de reivindicaciones laborales. Por ello, la actividad del sindicalismo solo puede comprenderse como expresión organizativa de un contexto de guerra revolucionaria y donde ---según el dirigente sindical Barrantes--- debe de tenerse en cuenta para su comprensión:

La relación simbiótica entre dirigentes sindicales y políticos; y de pronto nosotros teníamos un directorio que era político, político- militar. Nosotros veníamos de volar tiros contra Somoza, entonces teníamos una combinación de líderes que luchaban por el tema de la democracia y todo esto que te permite las organizaciones sindicales pero también con la formación de liderazgo guerrillero... el jefe, que te enseñó que había una disciplina en la estructura combatiente del Frente. (Barrantes Comunicación personal, 2 de abril 2015).

La concepción revolucionaria que impregnó la dinámica de los sindicatos, orientaba sus actividades a los lineamientos institucionales de la revolución, teniendo como resultado una estrecha vículación organizativa entre estos y el FSLN (Vilas, 1986, 1987; Middlebrook, 1997).). En este escenario sociopolítico, la dinámica de la acción colectiva del sindicalismo nicaragüense estuvo dominada por la contienda contenida, debido a que la misma se desarrollaba en el marco normativo establecido por la Revolución Popular Sandinista. 
En el periodo Neoliberal (1990-2006) el sindicalismo reenfoca sus repertorios de lucha, dado los cambios de la estructuras de oportunidades que representó la derrota electoral del FSLN y la instauración de un gobierno neoliberal. Durante este periodo la flexibilización laboral promovida por el neoliberalismojugó un papel muy importante en la configuración del movimiento sindical pues:

Fue tanto el avance que tuvieron ellos (capitalistas) que de pronto ya no necesitaban tenernos en la fábrica. Porque muchas de esas piezas las hacían en los hogares, contrataban gente y en las comunidades hacían esas piezas, y eso vino a debilitar la estructuración de los sindicatos que teníamos en la industria automotriz por ejemplo. O los sindicatos poderosos que tuvimos en el acero, o los sindicatos poderosos que se tuvieron en las minerías, en el carbón (Barrantes comunicación, personal, 2 de abril 2015).

El movimiento de trabajadores fue muy afectado por los ajustes estructurales derivados de las políticas neoliberales aplicadas en la década de los 90 en el marco de la transición política de la época (Rovira, 2009). En este escenario, el movimiento sindical sufrió un serio revés en relación a los derechos sociales conquistados durante la Revolución en la década del 80:

Solo en el primer año de Doña Violenta, fueron 95 mil trabajadores que nos fuimos a la calle, y fueron trabajadores que se fueron a la calle sin ninguna prestación; porque nosotros perdimos la conversión colectiva, perdimos los contratos de trabajos, perdimos el seguro social y por ende, entonces nosotros nos rezagamos en la capacitación técnica y profesional, y porque no decir que también académica. Porque a la par también del despido que se dio vino también la privatización de la salud, vino la privatización de la educación, vino la privatización del transporte, vino la privatización de las comunicaciones (Adrián Martínez, Comunicación personal, 20 del marco 2015).

El proyecto neoliberal de debilitamiento de los movimientos de trabajadores se reflejó en tres decisiones del gobierno de Violeta Barrios: 1) desconocimiento de todos los convenios colectivos que se habían firmado durante la revolución; 2) suspensión de las cotizaciones sindicales que estaban establecidas por ley; 3) la promoción de los denominados "sindicatos blancos" (StahlerSholk, 1994). El desconocimiento del gobierno de Violeta Barrios de las reivindicaciones laborales que se habían alcanzado durante la revolución ocasionaron un sin número de huelgas, que hicieron de este período uno de los más álgidos en la historia del movimiento de trabajadores nicaragüenses.

El desconocimiento de los convenios colectivos, tuvo como objetivo crear el camino al proceso de privatización, dado que estos convenios garantizaban muchos derechos a los trabajadores y sus organizaciones (Guevara, 2008; Stahler-Sholk, 1994). Paralelamente, el gobierno de Violeta Barrios procedió a suspender las cotizaciones que los trabajadores daban por ley a los sindicatos, disminuyendo sustancialmente los recursos con que contaban las organizaciones de trabajadores para su lucha. A pesar de la reducción de las cotizaciones, los sindicatos sandinistas intensificaron su oposición. Por su parte, el gobierno creó los "sindicatos blancos", también denominados "democráticos", para atomizar y debilitar al movimiento de resistencia de los trabajadores sandinistas. En esta década, como estrategia contra las políticas neoliberales, el FSLN creó el Frente Nacional de los Trabajadores (FNT), con el fin de organizar y articular a las diferentes centrales de trabajadores, y así garantizar una resistencia más fuerte ante las políticas que los gobiernos de esta década implementaron. 
Durante este decenio, el sindicalismo nicaragüense contó con mayor experiencia y habilidad para la formulación de propuesta y negociación con los actores del sector público y privado. En este marco, los repertorios del movimiento sindical se caracterizaron por la combinación de contienda transgresiva y contenciosa: por un lado, la protesta pública, las huelgas, los paros laborales, y por otro, las negociaciones con el gobierno. El sindicalismo nicaragüense también buscó la diversificación y amplitud de alianzas. Con estas nuevas propuestas el movimiento trató de posicionarse de manera estratégica en los nuevos sectores de la economía neoliberal, como fueron los movimientos de mujeres trabajadoras en las maquilas, y los movimientos de trabajadores por cuenta propia.

En este periodo producto del desarrollo de las maquilas emergen los sindicatos de mujeres, lo que fue una nueva estructura de oportunidades que imprimió cierta innovación en los repertorios del sindicalismo nacional. Dicha innovación consistió en poner de manifiesto la doble dominación de la mujer: en el ámbito público a través de explotación fabril, y en el privado, por medio de la violencia de género dirigida estas mujeres trabajadoras (Guevara, 2008).

Por otro lado, el movimiento de trabajadores por cuenta propia surgió como necesidad de hacer frentea las condiciones socioeconómicas producidas por las políticas neoliberales, que hicieron crecer la economía informal y la precarización de muchos de los trabajadores que eran parte de la empresa privada y el Estado (Núñez, 2011). En esta lógica, Adrián Martínez presidente de dicho movimiento, define al movimiento de trabajadores por cuenta propia desde:

Un concepto ideológico y político, porque eso te da unidad, eso te da solidaridad, eso te da compañerismo y no es el individualismo y no es la concentración tampoco de capital. Entonces por eso que se hace diferente a esta organización, entonces por eso nosotros decimos que es una organización sindical de nuevo tipo (Comunicación personal, 20 de marzo 2015).

En este contexto, la economía social solidaria como propuesta alternativa del movimiento de trabajadores por cuenta propia a la economía de mercado, pretende una equitativa distribución de la riqueza mediante la asociatividad como forma de organización. Un mercado alternativo basado en precios justos es decir: "una economía asociativa y autogestionaria," (Comunicación personal, 20 de marzo 2015).

\section{Conclusiones y resultados más importantes}

En la acción colectiva del sindicalismo, tanto las plataformas sociopolíticas como las vinculaciones con el FSLN fueron de mucha relevancia en la modelación de los resultados de la contienda política. Estos resultados a su vez han contribuido a un proyecto de izquierda, consistiendo en: 1) combinación de la contienda contenida y la contienda transgresiva durante el somocismo durante la década de los 70 y durante el periodo neoliberal (década de los 90; 2) democratizaron de los derechos sociales y políticos: convenios colectivos, libertad sindical y reivindicaciones salariales (década de los 80); 3) el paso de una subordinación que obedecía un modelo vanguardia política (FSLN) hacia una forma de organización más autónoma: (década de los 80 y 90); 4) reconfiguración de una identidad sindical basada una ideología marxista hacia formas organizativas autogestionaria y de libre mercado (socialismo libertario);5) creación de proyectos alternativos a la economía de mercado, como la economía social solidaria, en el caso de la CTCP, y de género, en el caso del movimiento de mujeres; 6) combinación de reivindicaciones socioeconómicas con propuestas sociopolíticas (negociaciones 
y alianzas durante la década de los 90 y 2000); 7) predominio actual de la contienda contenida sobre la transgresiva.

Estos resultados sociopolíticos y económicos son el fruto por un lado de los repertorios como las huelgas, la lucha armada y las alianzas. Por otro lado, las estructuras de oportunidades, como los tejidos de alianza la división de las elites han modelado el tipo la contienda política del sindicalismo nicaragüense hasta nuestros días.

\section{Referencias bibliográficas}

Aya, R. (1990). Rethinking Revolutions and Collective Violence. Studies on Concept, Theory, and Method. Amsterdam: Het Spinhuis.

Bobbio, N. (1996). Derecha e izquierda: razones y significados de una distinción política. Madrid: Taurus.

Centro de Análisis Sociocultural (2015). Movimientos Sociales y Acción colectiva en Nicaragua. Managua. Autor.

Guevara, O. (2008). Cien años del Movimiento Social en Nicaragua: relato cronológico. Managua: Instituto de Historia de Nicaragua y Centroamérica.

Gutiérrez, G. (1985). Historia del movimiento obrero en Nicaragua (1900-1977). En P. González-Casanova. (Coord.), Historia del movimiento obrero en América Latina. México: Siglo Veintiuno Editores (pp. 196-252). México: Siglo XXI.

Middlebrook, K. \& Guerrero, M. (1997). Movimiento obrero y democratización regímenes posrevolucionarios: las políticas de transición en Nicaragua, Rusia y México. Foro Internacional, 365-407.

McAdam, D., Tarrow, S. y Tilly, C. (2005). Dinámica de la contienda política. Barcelona, Editorial Hacer.

Núñez, O. (2011). La economía social solidaria en las naciones proletarizadas y el proletariado por cuenta propia en la transformación del sistema. Managua: Consejo Latinoamericano de Ciencias Sociales \& Centro Interuniversitario de Estudios Latinoamericanos y Caribeños.

Rovira, J. (2009). Nicaragua 1979-2007. Transición a la democracia y perspectivas de su consolidación. Encuentro, 82, 6-24.

Stahler-Sholk, R. (1994). El ajuste neoliberal y sus opciones: la respuesta del movimiento sindical nicaragüense. Revista Mexicana de Sociología, 56(3), 59-88.

Sautu, R., Boniolo, P., Dalle, P. \& Elbert, R. (2005). Manual de metodología. Construcción del marco teórico, formulación de los objetivos y elección de la metodología. Buenos Aires: Consejo Latinoamericano de Ciencias Sociales.

Tarrow, S. (1997). El poder en movimiento. Los movimientos sociales, la acción colectiva y la política. Madrid: Alianza Editorial.

Tilly, C. (2007). La violencia colectiva. Barcelona: Editorial Hacer.

Torres, E \& Gomariz,E. (2007). ¿Qué significa ser de izquierda? Costa Rica: Facultad Latinoamericana de Ciencias Sociales.

Vilas. C. (1987) La Revolución Sandinista. Buenos Aires: Legasa. 